\title{
ORIGINAL ARTICLE \\ Patterns of population genetic variation in sympatric chiltoniid amphipods within a calcrete aquifer reveal a dynamic subterranean environment
}

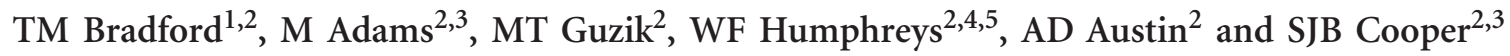 \\ Calcrete aquifers from the Yilgarn region of arid central Western Australia contain an assemblage of obligate groundwater \\ invertebrate species that are each endemic to single aquifers. Fine-scale phylogeographic and population genetic analyses of \\ three sympatric and independently derived species of amphipod (Chiltoniidae) were carried out to determine whether there were \\ common patterns of population genetic structure or evidence for past geographic isolation of populations within a single \\ calcrete aquifer. Genetic diversity in amphipod mitochondrial DNA (cytochrome $c$ oxidase subunit I gene) and allozymes were \\ examined across a $3.5 \mathrm{~km}^{2}$ region of the Sturt Meadows calcrete, which contains a grid of 115 bore holes (=wells). Stygobiont \\ amphipods were found to have high levels of mitochondrial haplotype diversity coupled with low nucleotide diversity. \\ Mitochondrial phylogeographic structuring was found between haplogroups for one of the chiltoniid species, which also showed \\ population structuring for nuclear markers. Signatures of population expansion in two of the three species, match previous \\ findings for diving beetles at the same site, indicating that the system is dynamic. We propose isolation of populations in \\ refugia within the calcrete, followed by expansion events, as the most likely source of intraspecific genetic diversity, due to \\ changes in water level influencing gene flow across the calcrete.
}

Heredity (2013) 111, 77-85; doi:10.1038/hdy.2013.22; published online 3 April 2013

Keywords: Stygofauna; mitochondrial DNA; allozymes; population genetic structure

\section{INTRODUCTION}

The evolution of subterranean fauna has been proposed to result mainly from colonisation by surface species, and with diversification either occurring independently from surface ancestors due to their extinction as a result of climate change (climate-relict hypothesis; Barr, 1968), or by adaptation to the subterranean environment in the presence of reduced gene flow with the surface ancestor (adaptiveshift hypothesis: Peck and Finston, 1993; Desutter-Grandcolas and Grandcolas, 1996). Support for both the climate-relict and adaptiveshift hypotheses has come from phylogenetic and phylogeographic studies, comparing subterranean and closely related or sister surface species ( Peck and Finston, 1993; Rivera et al., 2002; Leys et al., 2003; Niemiller et al., 2008; Villacorta et al., 2008). There is recent evidence that subterranean species may evolve within cave systems from ancestral species that are already adapted to subterranean life (Faille et al., 2010; Juan et al., 2010; Ribera et al., 2010). However, few studies have investigated what diversifying forces may operate within subterranean environments to promote genetic divergence and speciation (reviewed by Juan et al., 2010). The calcrete aquifers (calcretes) of the Yilgarn region of Western Australia are an ideal system for such a study, due to their isolation from each other and their unique diversity of endemic subterranean invertebrates (Guzik et al., 2010), the surface ancestors of which are regionally extinct in this now arid region.
Calcrete deposits of the Yilgarn region of central Western Australia are thought to have formed from the groundwater flow between 30-10 Mya (Morgan, 1993). Over 200 major calcretes are found in the Yilgarn and they provide habitat for subterranean aquatic invertebrates (referred to as stygofauna), such as dytiscid diving beetles and a variety of crustaceans, including Amphipoda, Isopoda, Bathynellacea and Copepoda (Watts and Humphreys, 2004; Guzik et al., 2010). The evolution of obligate subterranean species is thought to have resulted from their physical isolation in individual calcretes, such that new species were formed due to allopatric divergence from their surface ancestors (Cooper et al., 2002; Leys et al., 2003; Guzik et al., 2009). However, the presence of multiple independent cases of sympatric sister species of diving beetles in separate size classes raises the potential for speciation to have occurred underground within the calcrete environment, possibly via ecological niche partitioning and/or allopatric divergence at a micro-geographic scale (ie, micro-allopatry; Cooper et al., 2002; Leys et al., 2003; Leys and Watts, 2008; Leijs et al., 2012).

To explore the latter hypothesis, Guzik et al., 2009, 2011 investigated population structuring at two spatial scales in the Yilgarn calcretes, using a multi-species approach and a mitochondrial DNA (mtDNA) marker. Evidence for the operation of micro-allopatric processes was found in a sister-species triplet of diving beetles (Dytiscidae) over a $2.5 \mathrm{~km}$ distance, and isolation by distance was identified in two out of the three species (Guzik et al., 2009). Over a

${ }^{1}$ CSIRO Land and Water, Urrbrae, SA, Australia; ${ }^{2}$ Australian Centre for Evolutionary Biology and Biodiversity, School of Earth and Environmental Sciences, The University of Adelaide, Adelaide, SA, Australia; ${ }^{3}$ Evolutionary Biology Unit, South Australian Museum, North Terrace, Adelaide, SA, Australia; ${ }^{4}$ Collections and Research Centre, Western Australian Museum, Welshpool, WA, Australia and ${ }^{5}$ School of Animal Biology, University of Western Australia, Nedlands, WA, Australia

Correspondence: Dr TM Bradford, CSIRO Land and Water, Waite Rd Urrbrae, Adelaide, SA 5064, Australia.

E-mail: tessa.bradford@csiro.au

Received 17 December 2012; accepted 25 February 2013; published online 3 April 2013 
broader distance of up to $15 \mathrm{~km}$ in a separate calcrete, three diving beetle species, chiltoniid amphipods, and Haloniscus isopods all showed evidence for common patterns of population structure indicative of a past fragmentation event, followed by subsequent re-establishment of gene flow (Guzik et al., 2011). Therefore it appears that micro-allopatric processes may exist for stygobiont invertebrates within calcretes, but fundamental questions remain about what features of the calcrete environment (e.g. calcrete structure and water chemistry) are responsible for generating these phylogeographic patterns and whether calcrete aquifers are dynamic environments or relatively stable over millions of years (Guzik et al., 2011).

Our study further explores the nature of the calcrete environment and intra-specific population genetic structure at the Sturt Meadows calcrete through genetic analyses of three species of stygobiontic chiltoniid amphipods (Yilgarniella sturtensis, Scutachiltonia axfordi and Stygochiltonia bradfordae; King et al., 2012), sympatric with previously studied beetle taxa (Guzik et al., 2009). In contrast to the beetles, the three amphipod species are from separate evolutionary lineages that have colonised the calcrete, and Bayesian phylogenetic analyses have revealed between species mitDNA divergences of 11-13\% (Bradford et al., 2010). Phylogeographic analyses of beetles (Cooper et al., 2002; Leys et al., 2003) and other crustacean taxa (including chiltoniid amphipods; Cooper et al., 2007, 2008; Guzik et al., 2008) suggest that calcrete populations were isolated and hence, there has been an absence of permanent sources of surface water in the region for millions of years, implying a pre-Pliocene origin for the three amphipod species in the Sturt Meadows calcrete. Here we employ multiple genetic markers for the amphipods, including mitochondrial cytochrome $c$ oxidase subunit I (COI) sequence and allozyme data, in order to assess historical and contemporary patterns of population structure and demographic history. Identification of similar phylogeographic structure for amphipod species present at the same site is likely to indicate past barriers to gene flow, and congruent population genetic patterns across co-occurring stygofauna may be indicative of short-term allopatric processes operating within the calcrete. Using data from the lithology of drill cores, we also assessed the variability in characteristics of the calcrete, such as thickness and calcrete structure, and discuss their potential influence on patterns of population structure and demographic history.

\section{MATERIALS AND METHODS}

\section{Lithology of the drill cores}

The Sturt Meadows calcrete $\left(\sim 43 \mathrm{~km}^{2}\right)$ lies in the Raeside palaeodrainage system in the Yilgarn region of Western Australia. This calcrete deposit lies within a broad ephemeral drainage approximately $7 \mathrm{~km}$ north of the playa Lake Raeside (Figure 1a). The groundwater was accessed through mineral exploration bores that are uncased, save for a capped stabilising sleeve at the surface, in an area of $3.5 \mathrm{~km}^{2}$ (Figure la and b). The two adjacent rectilinear grids of

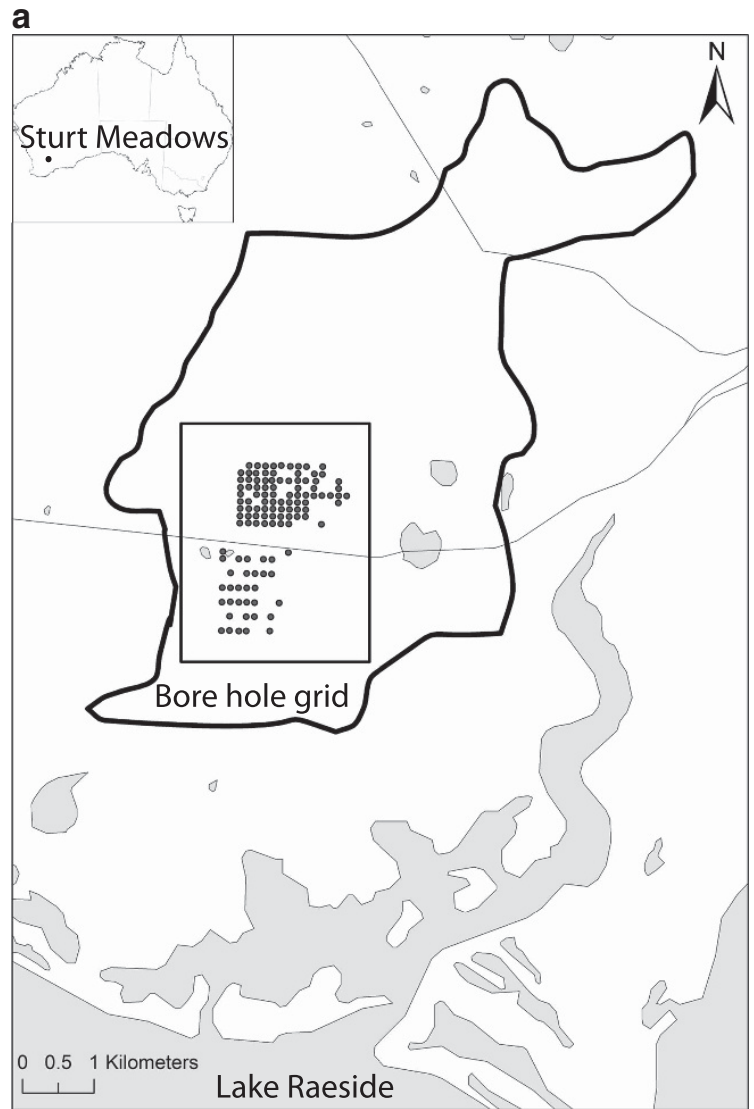

b
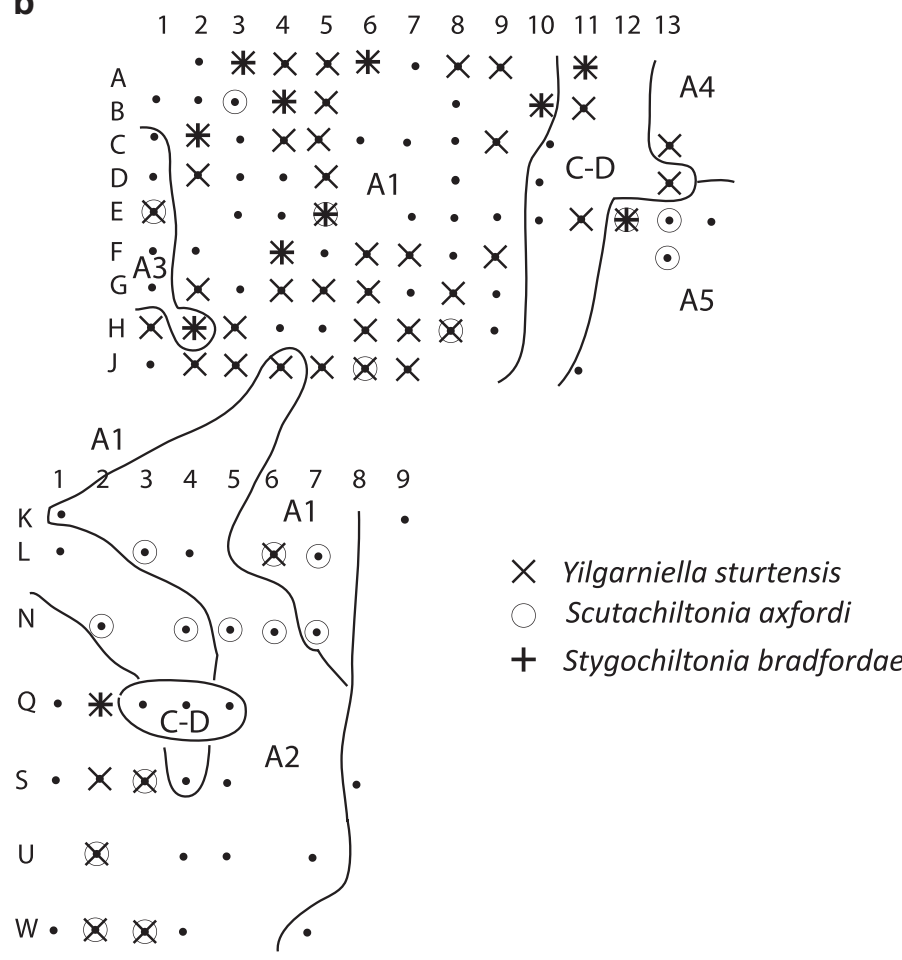

+ Stygochiltonia bradfordae

Figure 1 Geographical distribution of amphipod species at Sturt Meadows. (a), Map of Australia with the Sturt Meadows pastoral property in Western Australia marked. The expanded diagram shows the sample site at Sturt Meadows with the bore hole grid north and south of the road (grey line) outlined in a square. The shape of the calcrete is illustrated in black, and the salt lake and low lying areas that may contain water are shown in grey. (b), Distribution of chiltoniid species across the bore hole grid. Distribution of the lithology zones identified in this study (A1, A2, A3, A4, A5, C-D) in the grid are specified by black lines. Zone A1contains calcrete $\geqslant 11 \mathrm{~m} ; \mathrm{A} 2$, calcrete averages $6-8 \mathrm{~m}$ thick and overlies clay; $A 3,<5 \mathrm{~m}$ of calcrete overlying clay with up to $25 \%$ silica, A4, calcrete generally $<7 \mathrm{~m}$ thick overlying clay, A5, calcrete underlying 4-6 m clay; and C-D, clay with some calcrete. 
$>100$ exploration bores, spaced 100 or $200 \mathrm{~m}$ apart (Figure 1b), were drilled by Anaconda Nickel Limited, providing a unique resource for studying population genetic structure within the calcrete at a fine spatial scale. Their Technical Report 1252 (Item 11 845, https://wamex3.dmp.wa.gov.au/wamex3/) contained geological details obtained from the testing of $2 \mathrm{~kg}$ samples collected from the bores over $1 \mathrm{~m}$ depth intervals, including the presence of calcrete and clay.

A system of classification for the lithologies in each drill hole was devised for this study, as a way of summarizing the type and thickness of calcrete and clay in the soil surrounding each bore, in order to establish if variation in the underground environment show any correlation with population genetic patterns. Each drill core log was identified as A-combined vadose calcrete and phreatic calcrete with minor clay layers; B - combined vadose and phreatic calcretes with substantial clay content less than 50\%; C-clay with substantial calcrete content less than $50 \%$; or D-clay that includes minor calcrete in some samples. Vadose calcrete has formed within the soil profile above the water table, and phreatic calcrete has formed through evaporative precipitation from groundwater (Moussavi-Harami et al., 2009). Thickness of the calcrete in each bore was noted. Lithology zones identified from the drill cores were then mapped onto the bore hole grid (Figure 1b), and calcrete thickness and lithology type was linked to pairwise genetic distance between bores for Y. sturtensis (see below)

\section{Samples}

Intensive sampling was carried out from 2004-2005, by both hauling with a small weighted plankton net $(250 \mu \mathrm{m})$ and pumping, leading to the collection of 6254 stygobitic macro-invertebrate specimens (Allford et al., 2008). Four additional field trips were conducted from 2005-2009, with targeted sampling of bores previously found to contain amphipods. Overall, a total of 253 specimens were collected from 62 bores (Allford et al., 2008; Bradford et al., 2010). Three species of stygobiont chiltoniid amphipod are present in the Sturt Meadows calcrete aquifer, Y. sturtensis, Sc. axfordi and St. bradfordae (King et al., 2012). Amphipods collected were sequenced for COI (see below) and typed to species, based on clustering of groups of haplotypes by a Neighbour Joining analysis (Figure 3 in Bradford et al., 2010). This DNA barcoding approach has recently been found to reflect morphological characters, used by King et al., 2012 to describe the species. In total, 149 specimens of $Y$. sturtensis, 89 Sc. axfordi, and 15 St. bradfordae were collected (refer to Supplementary Material S1 for site locations, site specific sample sizes and COI haplotypes). The size of each animal varied from $2 \mathrm{~mm}-4 \mathrm{~mm}$, and only the larger specimens $(>3 \mathrm{~mm})$ of $Y$. sturtensis were analysed for allozymes (see below). Sturt Meadows calcrete is in remote central Western Australia, and due to funding limitations, it has not been possible to conduct additional field trips to increase the sample numbers of St. bradfordae.

\section{DNA extraction, amplification and sequencing}

One leg was removed from each amphipod and DNA extracted using the GENTRA method (Puregene) according to the manufacturer's protocol for fresh tissues. The amphipod body was then frozen in liquid nitrogen for allozyme electrophoresis or preserved in $100 \%$ ethanol as a voucher for taxonomic description. Partial mtDNA sequences $(638 \mathrm{bp})$ from the COI gene were PCR-amplified, using the arthropod universal primers of Folmer et al., 1994, and sequenced with Big Dye technology (methodological details in Bradford et al., 2010). Sequences were aligned by eye, and translation to amino acid level was used to assess the correctness of the alignment and the possible presence of nuclear paralogs.

Genealogical relationships among mtDNA sequences within each species of amphipod were estimated by constructing statistical parsimony networks in TCS 1.21 under a 95\% parsimony limit (Clement et al., 2000).

\section{Historical demography inferred from mtDNA}

Demographic analyses were carried out for each of the three amphipod species, in order to determine if similar population processes have shaped their history. Genetic diversity indices, haplotype diversity $(h)$, nucleotide diversity $(\pi)$ and number of polymorphic sites were calculated using the program DnaSP version 4.50.3 (Rozas et al., 2003). Spatial structure within species was investigated in the program Alleles In Space (AIS; Miller, 2005), which analyses inter-individual patterns of genetic and geographical variation. The extent of genetic differences (mtDNA) between adjacent sites was represented by Landscape Shape Plots generated in AIS. The X and Y coordinates on the landscape plot are the midpoints in each edge of the triangulation in a connectivity network between sampling locations, and genetic distance between observations (vertices of the triangles) is represented as surface heights (Miller, 2005).

Summary statistics for detecting non-neutral (eg expansion or selection) patterns of evolution, including Tajima's $\mathrm{D}(\mathrm{D})$, Fu's $F s(F s)$ and $\mathrm{R}_{2}$ were estimated in DnaSP (Rozas et al., 2003). Ten thousand coalescent simulations were carried out under a neutral infinite-sites model, to look for evidence of population expansion or selection/genetic hitchhiking. Mismatch distributions of pair-wise distances between haplotypes were derived and compared to a simulated distribution with parameters estimated under the sudden expansion model in ARLEQUIN v3.5 ( Excoffier and Lischer, 2010). In order to identify if any departures from neutrality were due to selection on the COI gene itself, the McDonald and Kreitman, 1991 test, which is insensitive to demographic changes when detecting purifying selection, was applied to the COI dataset, and the neutrality index, which compares synonymous and non-synonymous variation within and between species, was calculated for each group.

Isolation by distance (IBD) was investigated for each amphipod species using the Mantel test in AIS, following the approach of Slatkin, 1993. The correlation between genetic (uncorrected (p) distances between sequences) and geographical distance was found to be non-linear, so we also carried out spatial autocorrelation analyses using AIS.

\section{Linking the underwater geological environment with Yilgarniella} sturtensis population genetic differentiation

Due to the low sample numbers of Sc. axfordi and St. bradfordae, within bore pair-wise genetic distance was only calculated for Y. sturtensis (ARLEQUIN). The link between lithology of the drill cores and pair-wise genetic distance was investigated using the BIO-ENV procedure in PRIMER v6 (Clarke and Gorley, 2006). The rank correlation coefficient $(\rho)$ between the abiotic (Euclidean distance) and biotic (Bray-Curtis simmilarities) ressemblance matrices was calculated, and the variables that gave the best match of environmental and population genetic differentiation were estimated. Significance of the correlation was tested using 999 permutations of the raw data.

\section{Allozyme variation within Yilgarniella sturtensis}

Allozyme electrophoresis was performed on cellulose acetate gels (Cellogel; MALTA) according to the principles and procedures of Richardson et al., 1986. Details of enzyme and locus abbreviations, enzyme commission numbers, electrophoretic conditions and stain recipes are presented in Richardson et al., 1986. Allozymes were designated alphabetically and multiple loci, where present, were designated numerically, in order of increasing electrophoretic mobility.

To ensure that homogenates exhibited adequate enzyme activity after electrophoresis, only specimens $>3 \mathrm{~mm}$ body length were selected. The initial allozyme screen of amphipods from the Sturt Meadows calcrete found Sc. axfordi to be largely homozygous at multiple loci (Bradford et al., 2010), and as St. bradfordae were collected in low numbers, the allozyme study was carried out on loci found to be polymorphic in Y. sturtensis. Of the 26 enzymes that displayed banding patterns permitting allozymic interpretation, 10 were polymorphic in Y. sturtensis and together yielded 11 informative allozyme loci (Enol, G6pd, Got1, Got2, Gpi, Idh, Mpi, Pgm, PepA2, PepB, and Tpi). In total, 116 specimens of $Y$. sturtensis from 30 bores were subsequently genotyped at these 11 loci.

\section{Detection of genetic clusters from the Yilgarniella sturtensis allozyme dataset}

Statistical evidence for departure from Hardy-Weinberg expectations or linkage disequilibrium at the four individual sites with good sample sizes $(n>10$; B4, B11, F4, H2), and for the meta-population (all individuals with $n>2$ ), was assessed using the computer program GENEPOP version 3.4, with statistical significance adjusted using sequential Bonferroni correction for multiple tests (methodological details in Hammer et al., 2007). Levels of genetic divergence among these four individual bores with $n>10$ were also estimated using pairwise $\mathrm{F}_{\mathrm{ST}}$ values in ARLEQUIN. 
Although lithology data were summarised (see above) to investigate variation in calcrete structure across the bore grid, these data are limited and not sufficient to provide a basis for specific a priori hypotheses on population connectivity and structure. We, therefore, applied two different clustering approaches, Bayesian inference based on Hardy-Weinberg expectations and Principal Co-ordinates Analysis (PCO), to the multi-locus nuclear dataset to search for evidence of population structuring. Both employ individuals as the unit of analysis, and neither makes any a priori assumptions about connectivity within the calcrete.

Firstly, population genetic structure within Y. sturtensis was investigated using GENELAND version 3.0.0 (Guillot et al., 2008). The program GENELAND uses Bayesian inference of the parameters of the spatial model through the MCMC algorithm to identify clusters of individuals in Hardy-Weinberg equilibrium among the multi-locus genotypic data. The number of populations (k) was searched for in the clustering and geographic location was included in the analysis. The correlated allele model was used, as recommended for detecting subtle population structure (Guillot et al., 2008). The MCMC chain was run 10 times for 1000000 iterations in order to estimate $k$, with uncertainty on coordinates set to $50 \mathrm{~m}$ as a conservative estimate of home range size. Two genetic clusters were found. Ten runs were then carried out with $k=2$, and the run with the highest log posterior density was chosen to best represent the pattern in the data. A burn-in of 200000 generations was trimmed from the posterior in the post-processing. A contour map of the posterior mode of population membership was drawn to visualize genetic substructure within the study site, and F statistics calculated by GENELAND were used as a measure of genetic structuring.

Genetic structure within and between individual bores, and allozyme groups (identified in GENELAND), was evaluated by AMOVA in ARLEQUIN in order to estimate the proportion of genetic variation partitioned within and between subpopulations using the fixation indices $\mathrm{F}_{\mathrm{CT}}, \mathrm{F}_{\mathrm{ST}}$, and $\mathrm{F}_{\mathrm{SC}}$.

The multi-locus allozyme and mitochondrial haplogroup datasets were also subjected to a second clustering approach to assess genetic structure within Y. sturtensis. A PCO exploring the genetic affinities among individuals was first undertaken on the allozyme data, using the methodology of Hammer et al., 2007. Thereafter, individuals were labelled on the PCO according to both mtDNA haplogroup and GENELAND subpopulation. Mitochondrial DNA for the two bore groups identified above for Y. sturtensis were further analysed for summary statistics.

\section{RESULTS}

\section{Lithology derived from the drill core logs}

Analyses of the drill samples identified topsoil, clay and vadose calcrete, overlaying phreatic calcrete, which is over a clay/sand aquifer.
Both vadose and phreatic calcrete can contain groundwater. Mapping the summarized lithology data (see Supplementary Material S2) onto the bore grid showed that the calcrete deposit in the area covered by the grid lies mainly west of a roughly north-south trending clay zone (Zone C-D; Figure 1b), that approximately follows the present-day drainage feature (data not shown). The calcrete is divisible into two major and three minor local zones, interspersed with clay (Figure 1b). There is a clay zone in grid line $\mathrm{Q}$ that may provide a partial barrier to movement of groundwater in the southern part of the grid area. Topsoil was generally only $1-2 \mathrm{~m}$ thick. The combined calcrete thickness often reaches and may well exceed the common drill depth of $11 \mathrm{~m}$. The major zones A1 and A2 differ in thickness. Zone A2 is shallower and contains less calcrete.

\section{Species distribution}

The amphipod species have overlapping distribution patterns. All three species were sympatric in two (E5 and E12) out of the 62 bores where amphipods were collected and 19 bores contained two or more amphipod species (Figure 1b). Distribution was patchy for all three species, and Y. sturtensis was found in 45\%, Sc. axfordi in 17\% and St. bradfordae in $10 \%$ of bores.

\section{COI haplotype networks}

Partial COI sequences of 638bp were obtained for the 253 samples in the mtDNA dataset and all could be translated into amino acids with no unexpected stop codons or indels, suggesting they were derived from a functional COI gene from the mtDNA genome. Haplotype networks revealed population genetic diversity in the amphipods at this fine spatial scale. Networks were similar for Sc. axfordi and St. bradfordae (Figures $2 \mathrm{~b}$ and $\mathrm{c}$ ), consisting of one common haplotype distributed across the sampled landscape, which appears internal in the network. Phylogeographic structure was identified for Y. sturtensis (Figure 2a), and the two major haplotypes separated by nine mutational steps (ie, a p-distance of $1.4 \%$ ), were found roughly in the eastern (haplogroup 1a) and western (haplogroup 1b) parts of the bore hole grid (Figure 3a), which were also seen as two monophyletic groups in a previous phylogenetic analysis (Figure 3, Sturt Meadows Clade 1; Bradford et al., 2010). A radiation of singletons could be seen in the network tips for Y. sturtensis, from both of the common haplotypes (Figure 2a), and for St. bradfordae (Figure 2c), suggestive a

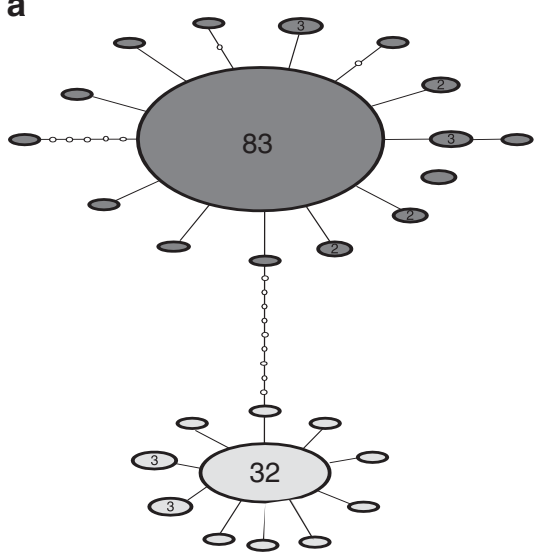

b

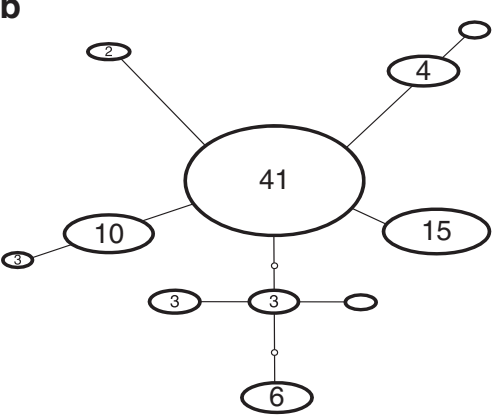

C

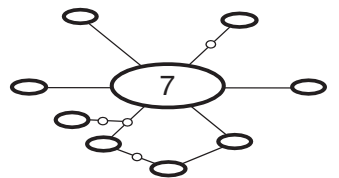

Figure 2 Statistical parsimony networks of mtDNA diversity. (a), Yilgarniella sturtensis, (b), Scutachiltonia axfordi and (c). Stygochiltonia bradfordae. Small open circles indicate un-sampled haplotypes and numbers in the ellipses are the sample size where greater than one. Lighter colour in the circles represents haplotype grouping (haplogroup) $1 \mathrm{a}$ and the darker colour haplogroup $1 \mathrm{~b}$ for $Y$. sturtensis. 
of a recent expansion event (Bandelt et al., 1995), or a locus undergoing selection (see below).

\section{Historical demography inferred from mtDNA}

Overall mtDNA diversity for each amphipod species is summarized in Table 1. Y. sturtensis was found in the largest numbers across the most bores, and had the most polymorphic sites of the three species. Levels of nucleotide diversity were low for all species examined, with $Y$. sturtensis at 0.006, slightly higher than Sc. axfordi and St. bradfordae at 0.003. In contrast to the low levels of nucleotide diversity, haplotype diversity was high and ranged between $0.65-0.80$.

The extent of difference between adjacent sites was investigated in Landscape Shape Plots. A distance weighting parameter $(a)$ of 1.0 and residual genetic distances were used for the genetic landscape shape interpolation analysis. Qualitatively similar results were obtained using raw genetic distances, different grid sizes, and a range of distance weighting parameters $(a=0.25-1)$. The highest level of mtDNA diversity was found between bores in the northern end of the bore field and lowest genetic diversity was among bores in the south-western corner, a pattern that was shared for all three species (Figures $4 \mathrm{a}-\mathrm{c}$ ). Thus, lithology zone A2 appears to be associated with decreased inter-individual genetic distances. Yilgarniella sturtensis, which had the largest sample size, showed more pockets of low genetic diversity in the southern end of the bore field that did not appear to be related to the number of individuals collected from these sites (Figure 4a). Sample size was a limitation for St. bradfordae, however the bores to the south were more closely related genetically (haplotype 30; Supplementary Material S1).

For the spatial autocorrelation analysis, five distance classes of varying sizes, containing nearly equal numbers of observations, were found to give a non-random pattern of genetic distance, which was significant for $S c$. axfordi $(P=0.003)$.

Negative values were found for the population genetic summary statistics Fs and D for all three amphipod species, suggesting a departure from the Wright-Fisher neutral model (Wright, 1931). Fs, $\mathrm{D}$ and $\mathrm{R}_{2}$ were significant only for St. bradfordae ( $F s=-0.061$, $\left.P=0.008 ; D=-0.081, P=0.032 ; R_{2}=0.147, P=0.005\right)$. There was no significant difference between the observed and expected mismatch distributions for St. bradfordae and Y. sturtensis under the sudden expansion model, however, the hypothesis of recent expansion was rejected for Sc. axfordi. The McDonald-Kreitman test found no significant differences indicative of selection acting on sites of the COI gene for the three amphipod species, though selection acting on other mtDNA genes linked to COI cannot be ruled out.

The best match between the environmental variables calcrete type and thickness, and pair-wise genetic distance within bores, was for calcrete thickness, however, this correlation was not significant (BIO:ENV; $\rho=0.093, P=0.53$ ).

\section{Allozyme variation within Yilgarniella sturtensis}

Allozyme allele frequencies were scored at the 11 loci found to be polymorphic for Y. sturtensis in the initial overview screen. Of the 116 individuals screened for $Y$. sturtensis, the number of samples per bore varied between one and 14, with 10 out of the 30 bores having only one individual sampled. The allele frequencies at these 30 sites for Y. sturtensis are presented in Supplementary Material S3. Average

Table 1 Molecular diversity indices for Yilgarniella sturtensis, Scutachiltonia axfordi and Stygochiltonia bradfordae

\begin{tabular}{lccccccc}
\hline Species & $\mathrm{n}$ & $\mathrm{n} /$ bore & \# bores & \# hap & \multicolumn{1}{c}{ S } & $\mathrm{h}$ & $\pi$ \\
\hline Y. sturtensis & 149 & $1-14$ & 52 & 25 & 37 & $0.645 \pm 0.004$ & $0.006 \pm 0.0050$ \\
Sc. axfordi & 89 & $1-35$ & 20 & 11 & 12 & $0.744 \pm 0.040$ & $0.0025 \pm 0.0030$ \\
St. bradfordae & 15 & $1-2$ & 11 & 9 & 10 & $0.800 \pm 0.108$ & $0.0026 \pm 0.0006$
\end{tabular}

Abbreviations: $n$, total number of individuals; $\mathrm{S}$, number of polymorphic sites; $h$, haplotype diversity; $\pi$, nucleotide diversity as average number of nucleotide differences per site between two sequences. a
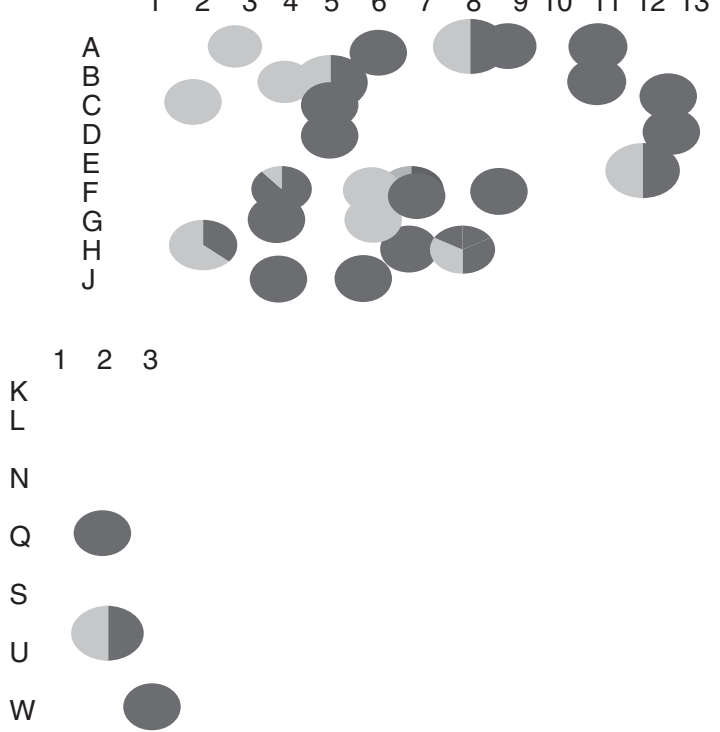

b $\begin{array}{llllllllllllll}1 & 2 & 3 & 4 & 5 & 6 & 7 & 8 & 9 & 10 & 11 & 12 & 13\end{array}$

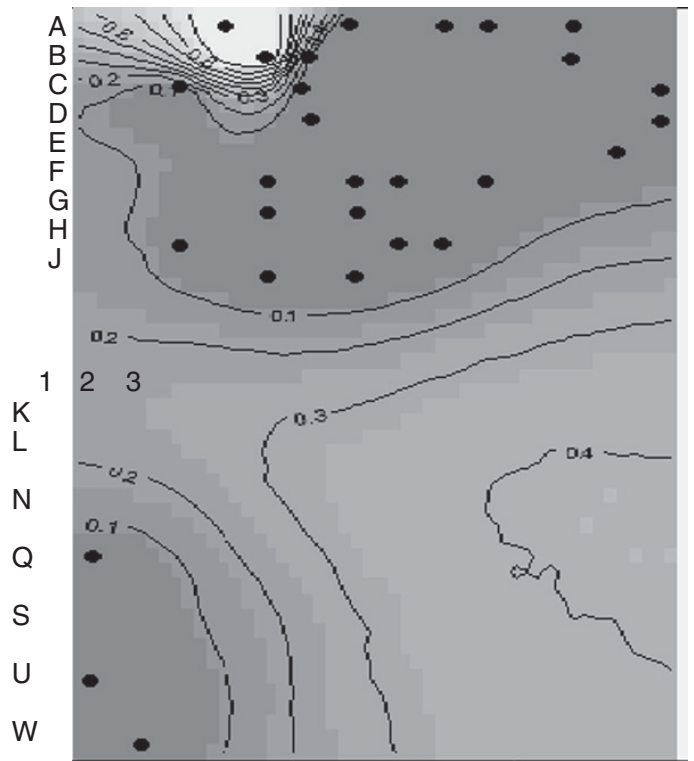

Figure 3 Population structure in Yilgarniella sturtensis. (a), Distribution of mtDNA haplogroup 1a (light) and haplogroup 1b (dark) across the bore hole grid. (b), Results of GENELAND analysis of population structure in allozyme allele frequencies, as a map of posterior probabilities of population membership (number of populations =2). Lighter areas correspond to higher probability to belong to allozyme group 1, and bores sampled are indicated by black dots. 

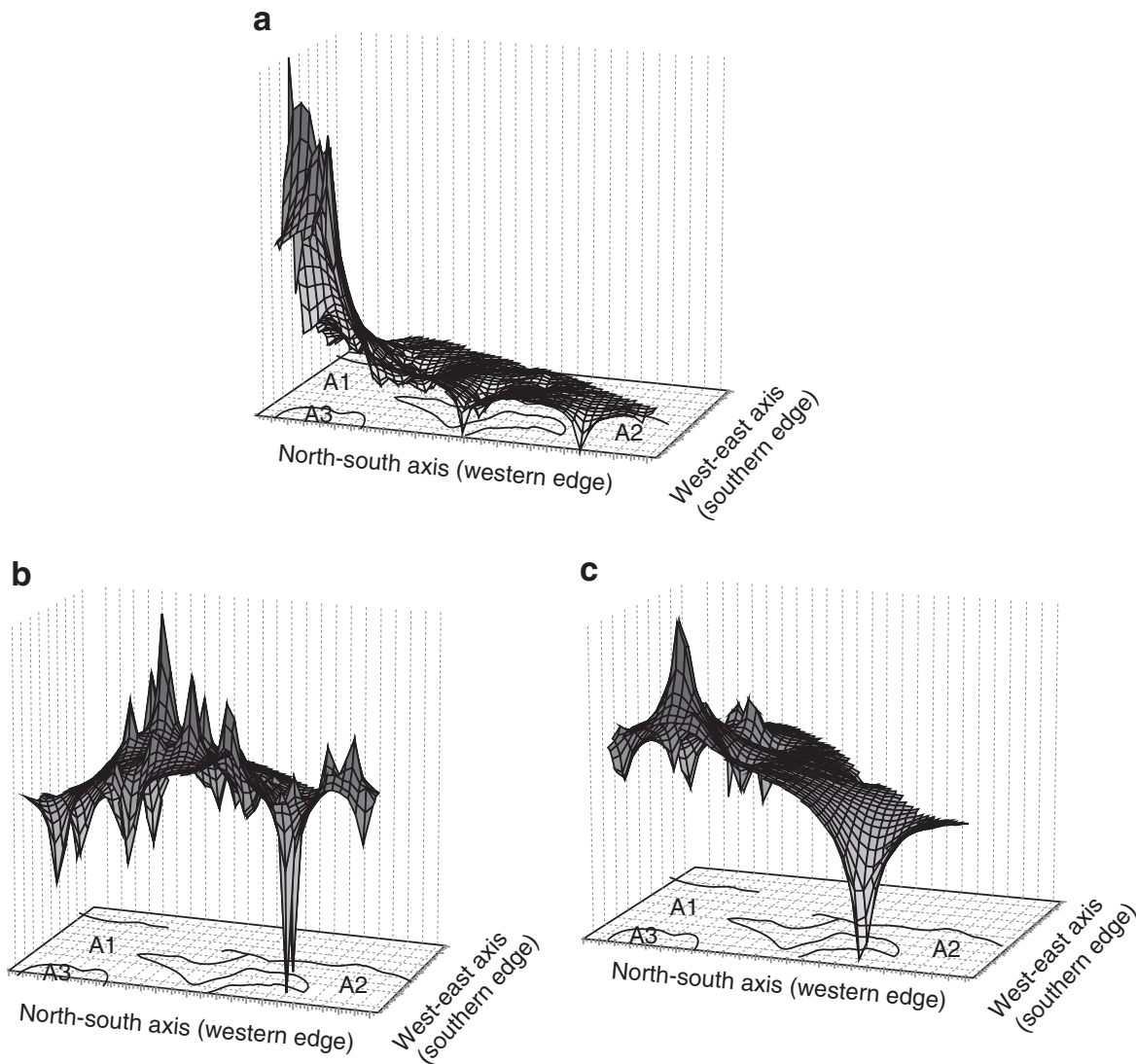

Figure 4 Results of genetic landscape shape interpolation analysis for the three species of amphipod using a distance weighting parameter (a) of 1.0 and residual genetic distances from mtDNA. $X$ and $Y$ axes correspond to geographic locations and surface plot heights reflect genetic distances. Higher genetic distances have a darker shading, and lower genetic distances lighter shading. (a), Yilgarniella sturtensis; (b), Scutachiltonia axfordi; (c), Stygochiltonia bradfordae. Locations of lithology zones A1 (calcrete $\geqslant 11 \mathrm{~m}$ ), A2 (calcrete $6-8 \mathrm{~m}$ ) and A3 (calcrete $<5 \mathrm{~m}$ ) on the landscape are shown.

Table 2 Pair-wise FST's between bores with $>10$ individuals for Yilgarniella sturtensis

\begin{tabular}{lcccc}
\hline & $B 4$ & $B 11$ & $F 4$ & $H 2$ \\
\hline B4 & 0 & & & \\
B11 & $0.1433(P<0.001)$ & 0 & & \\
F4 & $0.10322(P<0.001)$ & -0.0144 & 0 & \\
H2 & $0.14549(P<0.001)$ & $0.0659(P<0.001)$ & 0.0339 & 0 \\
\hline
\end{tabular}

asignificant at the $P<0.05$ level, with Bonferroni correction for multiple tests

number of alleles per locus was six, with the number of alleles ranging from three (Enol, Tpi, Gpt) to 13 (Gpi). Heterozygosity estimates were high in each bore, and varied between $0.167-0.583$ across the sites.

Assessment of genotype frequencies within species found no statistical evidence for departure from Hardy-Weinberg equilibrium (HWE) or linkage disequilibrium at the individual sites with $n>10$ (sites B4, B11, F4, and H2). However, there was a significant departure from HWE $(P=0.004)$ across the entire meta-population. A statistical assessment of pair-wise differences among the individual bores with $n>10$ found site B4 to be significantly different from each of the other three sites, but no significant heterogeneity among sites H2, F4 and B11 (Table 2).

Analysis of the entire allozyme dataset using GENELAND revealed two genetic clusters, with one comprising sites A3 $(n=1)$ plus B4
Table 3 AMOVA for the two allozyme bore groups of Yilgarniella sturtensis identified in the GENELAND clustering analysis

\begin{tabular}{lllrcc}
\hline $\begin{array}{l}\text { Number } \\
\text { of groups }\end{array}$ & $\begin{array}{l}\text { Source of } \\
\text { variation }\end{array}$ & $\begin{array}{c}\text { Variance } \\
\text { components }\end{array}$ & $\begin{array}{c}\% \text { of } \\
\text { variation }\end{array}$ & $\begin{array}{c}\text { Fixation } \\
\text { Indices }\end{array}$ & P-value \\
\hline 2 & Among bore groups & 0.2300 & 9.13 & $\mathrm{~F}_{\mathrm{CT}}=0.09$ & $P=0.035$ \\
& Within bore groups & 0.1517 & 6.02 & $\mathrm{~F}_{\mathrm{SC}}=0.07$ & $P<0.001$ \\
& Within bores & 0.0587 & 2.33 & $\mathrm{~F}_{\mathrm{IS}}=0.03$ & $\mathrm{NS}$ \\
& Within individuals & 2.07812 & 82.51 & $\mathrm{~F}_{\mathrm{IT}}=0.17$ & $P<0.001$
\end{tabular}

$P$-value is statistical significance; NS, not significant at the 0.05 probability level.

$(n=12)$, which were genetically distinct from the other sites (Figure 3b). Genetic differentiation between the two GENELAND groupings was evident across all allozyme loci, with a $\mathrm{F}_{\mathrm{ST}}$ value of 0.18 . Nine percent of variation was explained by groupings based on allele frequency, which was significant at the 0.05 level, and the majority of the variation was within individuals themselves (Table 3).

Comparison of the distribution of mitochondrial haplogroups and allozyme group membership across the bore field provided support for the presence of two partially-admixed genetic clusters in this region of the calcrete (Figures $3 \mathrm{a}$ and $\mathrm{b}$ ). Thirty-three individuals, typed for mtDNA, but not suitable for allozyme analyses, were removed from the Y. sturtensis dataset, so that mitochondrial haplogroup and allozyme group membership could be identified for each individual. When individuals were coded for mtDNA vs allozyme group, 13 


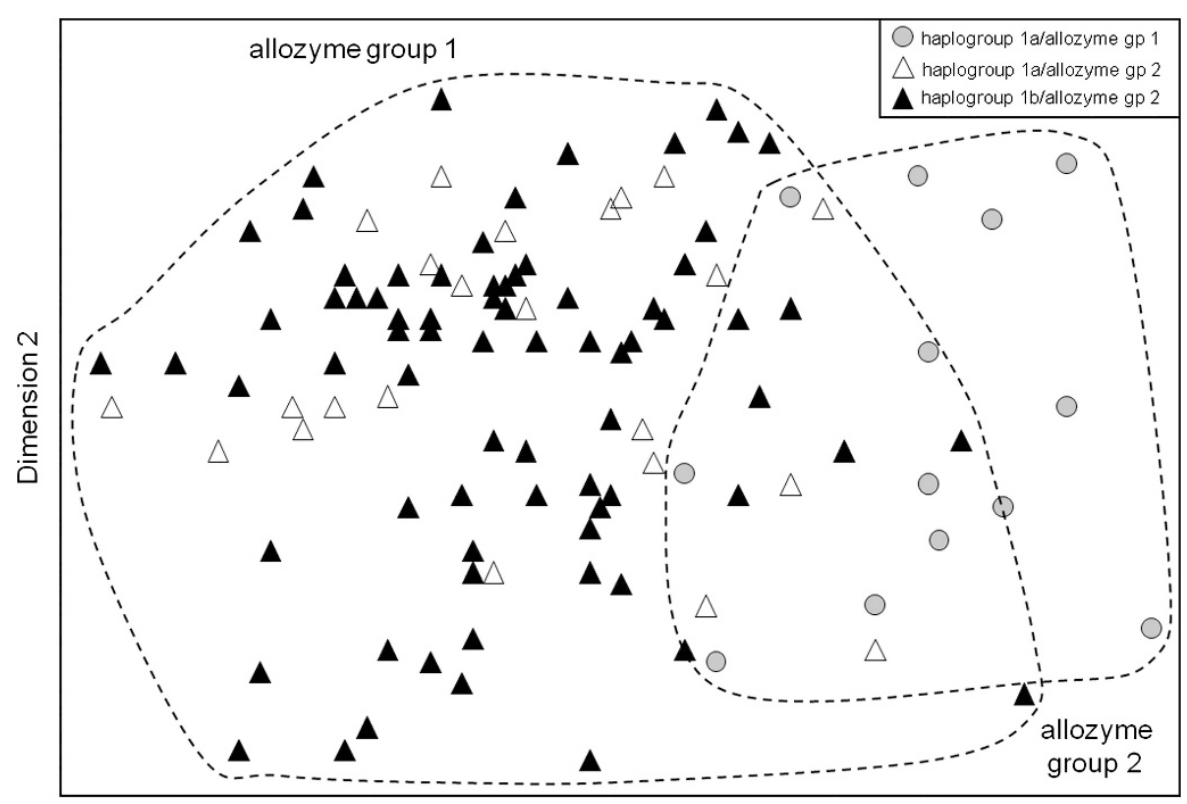

Dimension 1

Figure 5 Principle Co-ordinates Analysis (PCO) of allozyme allele frequencies for Yilgarniella sturtensis, showing mtDNA haplogroup and allozyme group membership of individuals. Three genetic populations were found; haplogroup 1a/allozyme group 1, haplogroup 1a/allozyme group 2, haplogroup $1 \mathrm{~b} /$ allozyme group 2. Allozyme groups are specified by a dotted line. The relative PCO scores have been plotted for the first (X-axis) and second ( $Y$-axis) dimensions.

individuals were found to be haplogroup 1a/allozyme group 1; 25 individuals to be haplogroup 1a/allozyme group 2; 78 individuals to be haplogroup 1b/allozyme group 2; and zero individuals belonged to haplogroup 1b/allozyme group 1. A Fishers Exact contingency test (two tailed) was significant $(P<0.0001)$ suggesting that the association of mtDNA haplogroup with allozyme group is non-random. Principle Co-ordinates Analysis (PCA) showed the two allozyme groups (1 and 2) to be overlapping (Figure 5). Haplogroup 1a/allozyme group 2 individuals, potentially representing the outcome of hybridization between the two genetic clusters, were allozymically indistinguishable based on the PCA, from haplogroup 1b/allozyme group 2 individuals (Figure 5), and were removed from subsequent analyses.

When mtDNA summary statistics were analysed for the two bore groups of $Y$. sturtensis, only haplogroup 1b/allozyme group 2 showed evidence for a statistically significant departure from the neutral model of evolution $(F s=-0.463, P=0.001 ; D=-0.093$, $\left.P=<0.001 ; R_{2}=0.097, P=0.018\right)$.

\section{DISCUSSION}

Recent research has shown that fine-level niche partitioning within cave environments, rather than adaptation to darkness and low resources, is a major factor in driving phenotypic evolution and community assemblage in subterranean ecosystems (Trontelj et al., 2012). This hypothesis has important implications for understanding the process of speciation of subterranean fauna, and the potential for 'speciation underground' which has recently been hypothesised for troglobiontic beetles in the Pyrenees (Faille et al., 2010; Ribera et al., 2010) and stygobiontic dytiscid beetles of the Yilgarn calcrete aquifers (Leys et al., 2003; Leijs et al., 2012). An essential ingredient in this process of adaptive evolution and speciation underground is genetic variation and it is important to understand how genetic diversity is both generated and maintained in subterranean populations following initial bottlenecks after colonisation by surface species (Barr, 1968). However, few studies have explored the potential for stygofauna and troglofauna to diversify genetically underground, largely because of the difficulty in sampling such populations. Here, we have been able to exploit a unique grid of mining exploration boreholes into a subterranean ecosystem to examine the distribution of genetic variation and population structure of three sympatric amphipod species. Overall, our analyses revealed contrasting patterns of genetic diversity within species, indicative of a dynamic environment, and further showed that genetic structuring of populations may occur at fine spatial scales, providing a basis for the maintenance of significant levels of genetic variation within species.

\section{Phylogeographic patterns and demographic events}

A spatial population genetic pattern was found in Y. sturtensis, based on both allozyme allele frequencies and mtDNA haplogroup. Two divergent haplotype groupings ( $1 \mathrm{a}$ and $1 \mathrm{~b}$ ) of $Y$. sturtensis were distributed roughly in the eastern and western parts of the bore field. These groupings overlapped, but were not completely concordant with the distribution of two populations identified by the multi-locus allozyme dataset, using both landscape genetic analyses across the bore field and analyses of differentiation among individual bores (pair-wise $\mathrm{F}_{\mathrm{ST}}$ ). Combining both datasets revealed a group of individuals that were potentially of 'hybrid origin' and indistinguishable allozymically from allozyme population 2 individuals, whilst retaining haplotype 1a. While it is possible that $Y$. sturtensis is actually two mitochondriallydifferentiated species, multivariate analysis on a suite of nuclear loci provided no support for the presence of separate taxa.

A similar haplotype network to Y. sturtensis, showing two divergent ( $\sim 1.4 \%$ p-distance) haplotype groups, was found for the diving beetle Paroster mesosturtensis (Guzik et al., 2009). However, there was no evidence for a spatial separation of haplotype groups, and the pattern was proposed to be the result of stochasticity in the process of lineage sorting of ancestral mtDNA haplotypes, or past geographic isolation of populations, followed by introgression, resulting in spatial mixing of the haplotype groups among the calcretes sampled (Guzik et al., 2009). That two species share such close similarities in 
mtDNA haplotype networks, albeit only with Y. sturtensis, seems unlikely to have resulted from stochastic lineage sorting, and rather suggests that the environment is not homogeneous and that spatial factors may exert a strong influence on population structure.

Possible signatures of population expansion were evident in two of the three amphipod species, and isolation by distance with no signal of expansion was identified in Sc. axfordi. However, homozygosity at multiple allozyme loci for Sc. Axfordi, but not Y. sturtensis and St. bradfordae (Bradford et al., 2010), suggests that Sc. axfordi may have experienced a population bottleneck. Two of the three co-occuring species also showed isolation by distance, and all three had signatures of population expansion (Guzik et al., 2009). Although we cannot rule out the possibility that departure from neutrality in all five species resulted from selection or genetic hitchhiking, this interpretation seems unlikely and we conclude therefore that the historical demography of these multiple stygobiont species reflects a calcrete environment that is highly dynamic.

Stygochiltonia bradfordae could either be rare, at the edge of its range and thus more abundant in other areas, or occupying a habitat that is difficult to sample. The different numbers of each species collected may be an indication of different micro-habitat preferences among the three species. Morphological differences in size and shape indicate the probable occupation of separate ecological niches, with St. bradfordae thought to be more likely to occupy the small interstitial spaces (King et al., 2012), from which they would be difficult to capture with a net or pump. Different micro-habitat preferences are a feature of the many different Niphargus amphipod species of Europe (Trontelj et al., 2012) and they also have been found in subterranean amphipods from the Pilbara (north-western Western Australia), where Nedsia sp. is associated with alluvial sediments, while Pilbarus millsi is restricted to areas of higher calcrete composition in the same catchment (Finston and Johnson, 2004). Signatures of population expansion without isolation by distance suggest that the St. bradfordae population is at the edge of its range (Carnaval et al., 2009). However, a current lack of bores across the remaining part of the Sturt Meadows calcrete does not permit additional sampling for comparison with population genetic patterns in other areas of the calcrete.

\section{The distribution of genetic diversity across the bore field}

Stygobiont amphipods at Sturt Meadows all had low levels of nucleotide diversity, but with high haplotype diversity in the range of $0.65-0.80$ as found in other stygofauna from the Yilgarn calcretes (Guzik et al., 2009, 2011). This pattern can result from population bottlenecks followed by range expansion leading to an excess of new mutations, so singletons are largely responsible for the high haplotype diversity (Avise, 1994). Range expansion followed by periods of isolation has also been identified as a mechanism for increased genetic variation in subterranean crayfish from the United States (Buhay and Crandall, 2005).

There was concordant variation in the distribution of genetic diversity for the amphipods across the calcrete, with low genetic diversity (p-distance among haplotypes) in the south of the bore grid (Figure 4). The diving beetles also showed spatial variation in genetic diversity, again with low genetic diversity in the southern sites (Guzik et al., 2009). Linked to this, the drill core data revealed an extremely heterogeneous lithological environment, as has been found for calcretes from the Lake Napperby area of central Australia where there is evidence for temporal changes in calcrete structure, due to post-Tertiary shifts in hydrologic zones (Arakel, 1986). In particular, the Sturt Meadow's calcrete appears to be significantly thicker in the north of the bore field $(\geqslant 11 \mathrm{~m})$ compared to the southern sites where the calcrete was $5-8 \mathrm{~m}$ thick. Calcrete thickness did give the best match to the multivariate pattern of intra-bore genetic diversity for $Y$. sturtensis, but this correlation was not significant, perhaps reflecting the lack of statistical power due to low numbers of individuals collected from many of the bores. Given that stygofauna in this region are entirely restricted to the calcrete matrix (Humphreys, 2008) and cannot disperse through the surrounding rock or clay, it is likely that when the water table is low and falls below the level of these shallow calcrete regions, populations will go extinct there. We propose therefore that the low genetic diversity in the southern portion of the bore grid may result from recent range expansion at a time of higher water table that followed a previous local extinction event.

We have recently monitored water levels in the Sturt Meadows calcrete and found variation of $\sim 40 \mathrm{~cm}$ following a single recharge event after prolonged drought (WF Humphreys, unpublished data). Recharge of the aquifer occurs after episodic heavy rain, characteristic of this arid region, resulting in variation in water table levels on a multi-year cycle (Humphreys et al., 2009), and presumably altering access by the stygobionts to different areas of the calcrete. Pleistocene climate fluctuations in the Australian arid zone (Byrne et al., 2008) would also have considerably influenced water levels in the aquifer, as elsewhere (English et al., 2001). During increased aridity associated with Glacial Maxima, water tables within the calcrete are likely to have fallen considerably. We hypothesize that these water level changes may have led to frequent isolation of populations in small areas containing the thicker regions of calcrete, which acted as refugia, so extinction of populations occurred outside of these areas. This process would have resulted in population bottlenecks, potentially in multiple refugia within the calcrete, leading to short-term population isolation (among refugia). Following re-charge of the aquifer, range expansion back into the shallow calcrete regions is likely to have occurred. We suggest that this dynamic process accounts for the high haplotype diversity seen in the three amphipod species and also in the diving beetles. It would also account for the persistence of divergent haplotypes in Y. sturtensis and the beetle species $P$. mesosturtensis, and the spatial patterns of population structure that are evident in Y. sturtensis.

\section{CONCLUSIONS}

There were no common divergence patterns evident from the mtDNA phylogeographies of the three amphipod species found at Sturt Meadows, suggesting that no long-term barriers to gene flow have been present within the sampled portion of the calcrete that affect all three species. Notwithstanding limitations in the dataset due to difficulties sampling this subterranean environment, the population genetic structure of $Y$. sturtensis, and evidence for isolation by distance in Sc. Axfordi, suggest that micro-allopatry cannot be ruled out as a potential diversifying force in the Sturt Meadows' calcrete. Combined with the high levels of genetic variation in the subterranean taxa, this spatial separation could provide a key ingredient to enable diversification and speciation underground (Juan et al., 2010).

Patterns of intraspecific genetic variation of stygobiont amphipods at Sturt Meadows, and in particular those of the most abundant species $Y$. sturtensis, indicate that the calcrete environment is dynamic with considerable variation in water levels potentially leading to short-term isolation of populations on a micro-geographic scale. The potential for multiple, independent, and localized population refugia has been identified at a larger spatial scale in multiple stygobiont species within a separate calcrete about $130 \mathrm{~km}$ east of Sturt Meadows (Guzik et al., 2011). The ability for stygobionts to disperse will be related to the different depths of calcrete, and linked to episodic recharge of the groundwater aquifer for range expansion. Thus, stygobiont species in calcrete aquifers will be impacted by lowering of 
the water table due to the combined pressures of anthropogenic intervention and climate change.

\section{DATA ARCHIVING}

DNA sequence data has been lodged on GenBank: accession numbers FJ785751-FJ785765; FJ785785-FJ785818.

\section{CONFLICT OF INTEREST}

The authors declare no conflict of interest.

\section{ACKNOWLEDGEMENTS}

We wish to thank Adam Allford, Lars Krogmann and Greg Collings for assistance in the field, and John Bradford for the analyses of the drill core data. We also thank Kathy Saint and Julianne Waldock for laboratory technical support, and Flora, Peter and Paul Axford for their warm hospitality at the Sturt Meadows pastoral property. We also thank Roger Butlin and Paul Sunnucks for providing valuable comments on earlier versions of the manuscript. Funding for this research was provided by ARC grants (DP0663675 and LP0348735) awarded to SJBC, WFH and ADA, and a Divisional Scholarship from the School of Earth and Environmental Sciences at The University of Adelaide awarded to TB.

Allford A, Cooper SJB, Humphreys WF, Austin AD (2008). Diversity and distribution of groundwater fauna in a calcrete aquifer: does sampling method influence the story? Invertebrate Systematics 22: 127-138.

Arakel AV (1986). Evolution of calcrete in palaeodrainages of the Lake Napperby area, central Australia. Palaeogeography, Palaeoclimatology, Palaeoecology 54: 283-303.

Avise JC (1994). Molecular Markers, Natural History, and Evolution. Chapman and Hall: New York.

Bandelt PJ, Forster P, Sykes BC, Richards MB (1995). Mitochondrial portraits of human populations using median networks. Genetics 141: 743-753.

Barr TCJ (1968). Cave ecology and the evolution of troglobites. In: Dobzhansky T, Hecht M, Steere WC (eds). Evolutionary Biology. Springer, USA, pp 35-102.

Bradford T, Adams M, Humphreys WF, Austin AD, Cooper SJB (2010). DNA barcoding of stygofauna uncovers cryptic amphipod diversity in a calcrete aquifer in Western Australia's arid zone. Molecular Ecology Resources 10: 41-50.

Buhay JE, Crandall KA (2005). Subterranean phylogeography of freshwater crayfishes shows extensive gene flow and surprisingly large population sizes. Molecular Ecology 14: 4259-4273.

Byrne M, Yeates DK, Joseph L, Kearney M, Bowler J, Williams MA et al. (2008). Birth of a biome: insights into the assembly and maintenance of the Australian arid zone biota. Molecular Ecology 17: 4398-4417.

Carnaval AC, Hickerson MJ, Haddad CFB, Rodrigues MT, Moritz C (2009). Stability Predicts Genetic Diversity in the Brazilian Atlantic Forest Hotspot. Science 323: 785-789.

Clarke KR, Gorley RN (2006). 'Primer v6: User manual/Tutorial'. (PRIMER-E, Plymouth.).

Clement M, Posada D, Crandall K (2000). TCS: a computer program to estimate gene genealogies. Molecular Ecology 9: 1657-1660.

Cooper SJB, Bradbury JH, Saint KM, Leys R, Austin AD, Humphreys WF (2007). Subterranean archipelago in the Australian arid zone: mitochondrial DNA phylogeography of amphipods from central Western Australia. Molecular Ecology 16: 1533-1544.

Cooper SJB, Hinze S, Leys R, Watts CHS, Humphreys WF (2002). Islands under the desert: molecular systematics and evolutionary origins of stygobitic water beetles (Coleoptera: Dytiscidae) from central Western Australia. Invertebrate Systematics 16: 589-598.

Cooper SJB, Saint KM, Taiti S, Austin AD, Humphreys WF (2008). Subterranean archipelago: mitochondrial DNA phylogeography of stygobitic isopods (Oniscidea: Haloniscus) from the Yilgarn region of Western Australia. Invertebrate Systematics 22: 195-203.

Desutter-Grandcolas L, Grandcolas P (1996). The evolution toward troglobitic life: phylogenetic reappraisal of climatic relict and local habitat shift hypotheses. Memoirs of Biospeology 23: 57-63.

English P, Spooner NA, Chappell J, Questiaux DG, Hill NG (2001). Lake Lewis basin, central Australia: environmental evolution and OSL chronology. Quaternary International 83-85: 81-101.

Excoffier L, Lischer HEL (2010). Arlequin suite ver 3.5: A new series of programs to perform population genetics analyses under Linux and Windows. Molecular Ecology Resources 10: 564-567.

Faille A, Ribera I, Deharveng L, Bourdeau C, Garnery L, Quéinnec E et al. (2010). A molecular phylogeny shows the single origin of the Pyrenean subterranean Trechini ground beetles (Coleoptera: Carabidae). Molecular Phylogenetics and Evolution 54: 97-106.

Finston TL, Johnson MS (2004). Geographic patterns of genetic diversity in subterranean amphipods of the Pilbara, Western Australia. Marine and Freshwater Research 55: 619-628.
Folmer O, Black M, Hoeh W, Lutz R, Vrijenhoek R (1994). DNA primers for amplification of mitochondrial cytochrome $\mathrm{c}$ oxidase subunit I from diverse metazoan invertebrates. Molecular Marine Biology and Biotechnology 3: 194-199.

Guillot G, Santos F, Estoup A (2008). Analysing georeferenced population genetics data with Geneland: a new algorithm to deal with null alleles and a friendly graphical user interface. Bioinformatics 24: 1406-1407.

Guzik MT, Abrams KM, Cooper SJB, Humphreys WF, Cho J-L, Austin AD (2008). Phylogeography of the ancient Parabathynellidae (Crustacea: Bathynellacea) from the Yilgarn region of Western Australia. Invertebrate Systematics 22: 205-216.

Guzik MT, Austin AD, Cooper SJB et al. (2010). Is the Australian subterranean fauna uniquely diverse? Invertebrate Systematics 24: 407-418.

Guzik MT, Cooper SJB, Humphreys WF, Ong S, Kawakami T, Austin AD (2011). Evidence for population fragmentation within a subterranean aquatic habitat in the Western Australian desert. Heredity 107: 215-230.

Guzik MT, Cooper SJB, Humphreys WF, Austin AD (2009). Fine-scale comparative phylogeography of a sympatric sister species triplet of subterranean diving beetles from a single calcrete aquifer in Western Australia. Molecular Ecology 18: 3683-3698.

Hammer MP, Adams M, Unmack PJ, Walker KF (2007). A rethink on Retropinna: conservation implications of new taxa and significant genetic sub-structure in Australian smelts (Pisces: Retropinnidae). Marine and Freshwater Research 58: 327-341.

Humphreys WF (2008). Rising from down under: developments in subterranean biodiversity in Australia from a groundwater fauna perspective. Invertebrate Systematics 22: 85-101.

Humphreys WF, Watts CHS, Cooper SJB, Leys R (2009). Groundwater estuaries of salt lakes: buried pools of endemic biodiversity on the western plateau, Australia. Hydrobiologia 626: 79-95.

Juan C, Guzik MT, Jaume D, Cooper SJB (2010). Evolution in caves: Darwin's 'wrecks of ancient life' in the molecular era. Molecular Ecology 19: 3865-3880.

King RK, Bradford T, Austin A, Humphreys WF, Cooper SJB (2012). Divergent molecular lineages and not-so-cryptic species: the first descriptions of stygobitic chiltoniid amphipods (Talitroidea: Chiltoniidae) from Western Australia. Journal of Crustacean Biology 32: 465-488.

Leijs R, van Nes EH, Watts CH, Cooper SJB, Humphreys WF, Hogendoorn K (2012). Evolution of blind beeltes in isolated aquifers: A test of alternative modes of speciation. PLOS ONE 7: 34260

Leys R, Watts CH (2008). Systematics and evolution of the Australian subterranean hydroporine diving beetles (Dytiscidae), with notes on Carabhydrus. Invertebrate Systematics 22: 217-225.

Leys R, Watts CH, Cooper SJ, Humphreys WF (2003). Evolution of subterranean diving beetles (Coleoptera: Dytiscidae: Hydroporini, Bidessini) in the arid zone of Australia. Evolution 57: 2819-2834.

McDonald JH, Kreitman M (1991). Adaptive evolution at the Adh locus in Drosophila. Nature 351: 652-654.

Miller MP (2005). Alleles In Space: Computer software for the joint analysis of Interindividual spatial and genetic information. Journal of Heredity 96: 722-724.

Morgan KH (1993). Development, sedimentation and economic potential of palaeoriver systems of the Yilgarn Craton of Western Australia. Sedimentary Geology 85: 637-656.

Moussavi-Harami R, Mahboubi A, Nadjafi M, Brenner RL, Mortazavi M (2009). Mechanism of calcrete formation in the Lower Cretaceous (Neocomian) fluvial deposits, northeastern Iran based on petrographic geochemical data. Cretaceous Research 30 : $1146-1156$

Niemiller ML, Fitzpatrick BM, Miller BT (2008). Recent divergence with gene flow in Tennessee cave salamanders (Plethodontidae: Gyrinophilus) inferred from gene genealogies, Molecular Ecology 17: 2258-2275.

Peck SB, Finston TL (1993). Galapagos Islands troglobites: the questions of tropical troglobites, parapatric distributions with eyed-sister-species, and their origin by parapatric speciation. Mémoires de Biospéologie 20: 19-37.

Ribera I, Fresneda J, Bucur R, Izquierdo A, Vogler AP, Salgado JM et al. (2010). Ancient origin of a Western Mediterranean radiation of subterranean beetles. BMC Evolutionary Biology 10: 29.

Richardson BJ, Baverstock PR, Adams M (1986). Allozyme Electrophoresis. Academic Press: Sydney.

Rivera MAJ, Howarth FG, Taiti S, Roderick GK (2002). Evolution in Hawaiian cave-adapted isopods (Oniscidea: Philosciidae): vicariant speciation or adaptive shifts? Molecular Phylogenetics and Evolution 25: 1-9.

Rozas J, Sánchez-DelBarrio JC, Messeguer X, Rozas R (2003). DnaSP, DNA polymorphism analyses by the coalescent and other methods. Bioinformatics 19: 2496-2497.

Slatkin M (1993). Isolation by distance in equilibrium and non-equilibrium populations. Evolution 47: 264-279.

Trontelj P, Blejek A, Fišer C (2012). Ecological convergence of cave communities. Evolution 66: 3852-3865.

Villacorta C, Jaume D, Oromi P, Juan C (2008). Under the volcano: phylogeography and evolution of the cave-dwelling Palmorchestia hypogaea (Amphipoda, Crustacea) at La Palma (Canary Islands). BMC Biology 6: 7.

Watts CHS, Humphreys WF (2004). Thirteen new Dytiscidae (Coleoptera) of the genera Boongurrus Larson, Tjirtudessus Watts and Humphreys and Nirripirti Watts and Humphreys, from underground waters in Australia. Transactions of the Royal Society of South Australia 128: 99-129. 